Supplement of Saf. Nucl. Waste Disposal, 1, 33-34, 2021

https://doi.org/10.5194/sand-1-33-2021-supplement

(C) Author(s) 2021. CC BY 4.0 License.

Supplement of

\title{
Development and testing of a tool for the decontamination of corners and inner edges on concrete surfaces
}

Shanyao Zhang et al.

Correspondence to: Shanyao Zhang (shanyao.zhang@kit.edu)

The copyright of individual parts of the supplement might differ from the article licence. 


\section{Development and testing of a tool for the decontamination of corners and inner edges on concrete surfaces}

Funded by the Federal Ministry of Education and Research (BMBF) as part of the FORKA - Research for the Decommissioning of Nuclear Facilities funding measure. Funding code BMBF: 15S9416A

\section{State of the Art}

- Decontamination of corners, inner edges, gaps and other geometrical discontinuities ist a huge challenge because of the lack of suitable tools.

- These corners and geometrical discontinuities are difficult to access or are located overhead, for example with inner edges and corners on ceilings.

- The combination of using heavy hand operated tools with exhaust systems, on difficult to access areas as well as the forces and vibration of the tools, make the task of decontamination a burden and cause the operators additional physical stress.
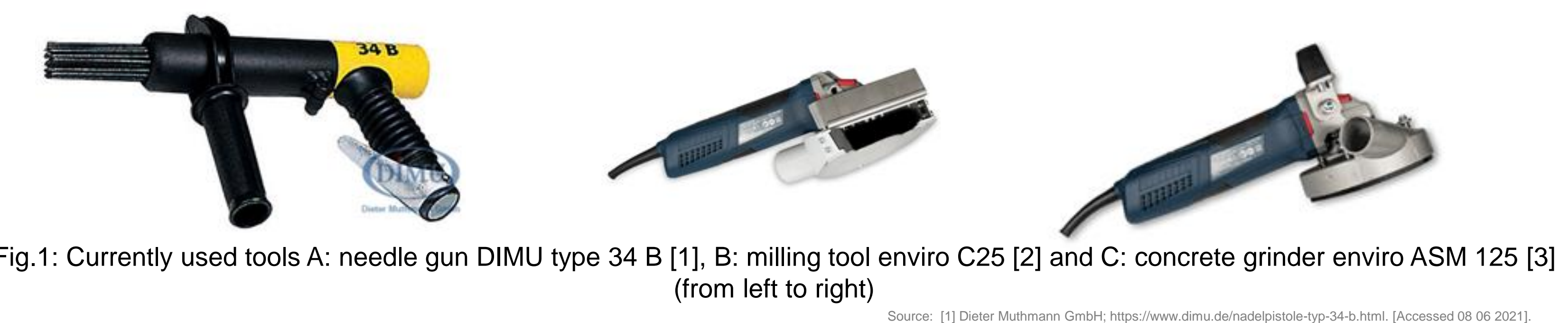

\section{Aim of the Project}

- Development of an innovative, semi-automated demonstrator for drymechanical decontamination of corners, edges and geometrical discontinuities in nuclear facilities

- The scientific investigation of experimentally collected performance parameters, such as feed rate, forces and torques, removal depth per operation, surface roughness, vibrations,

\section{Development of the prototypes}
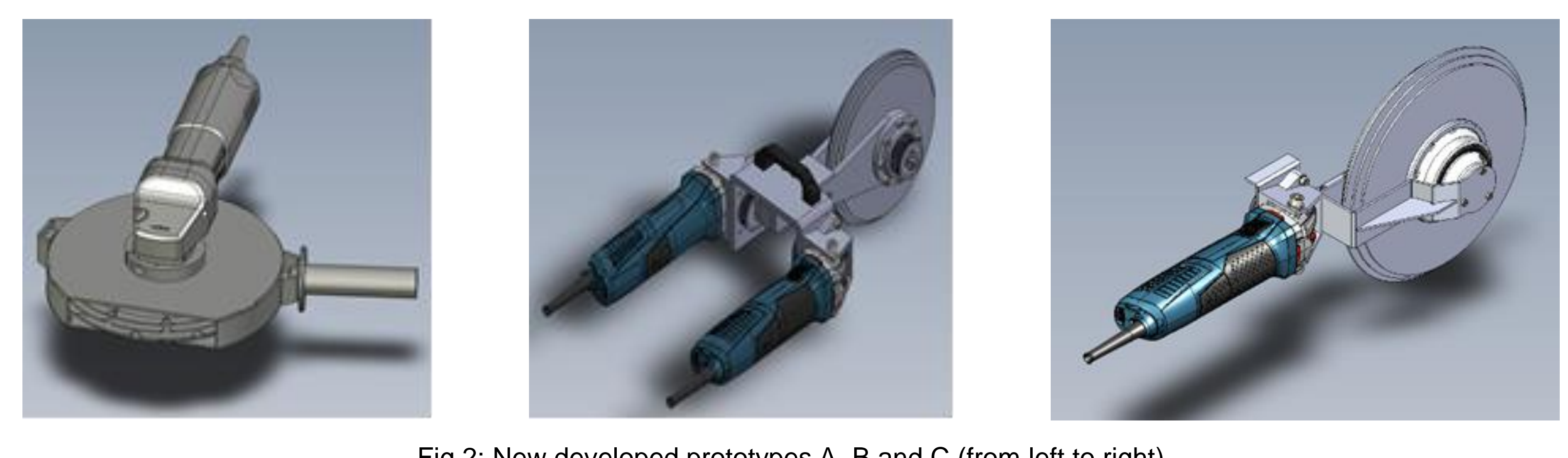

Fig.2: New developed prototypes A, B and C (from left to right)
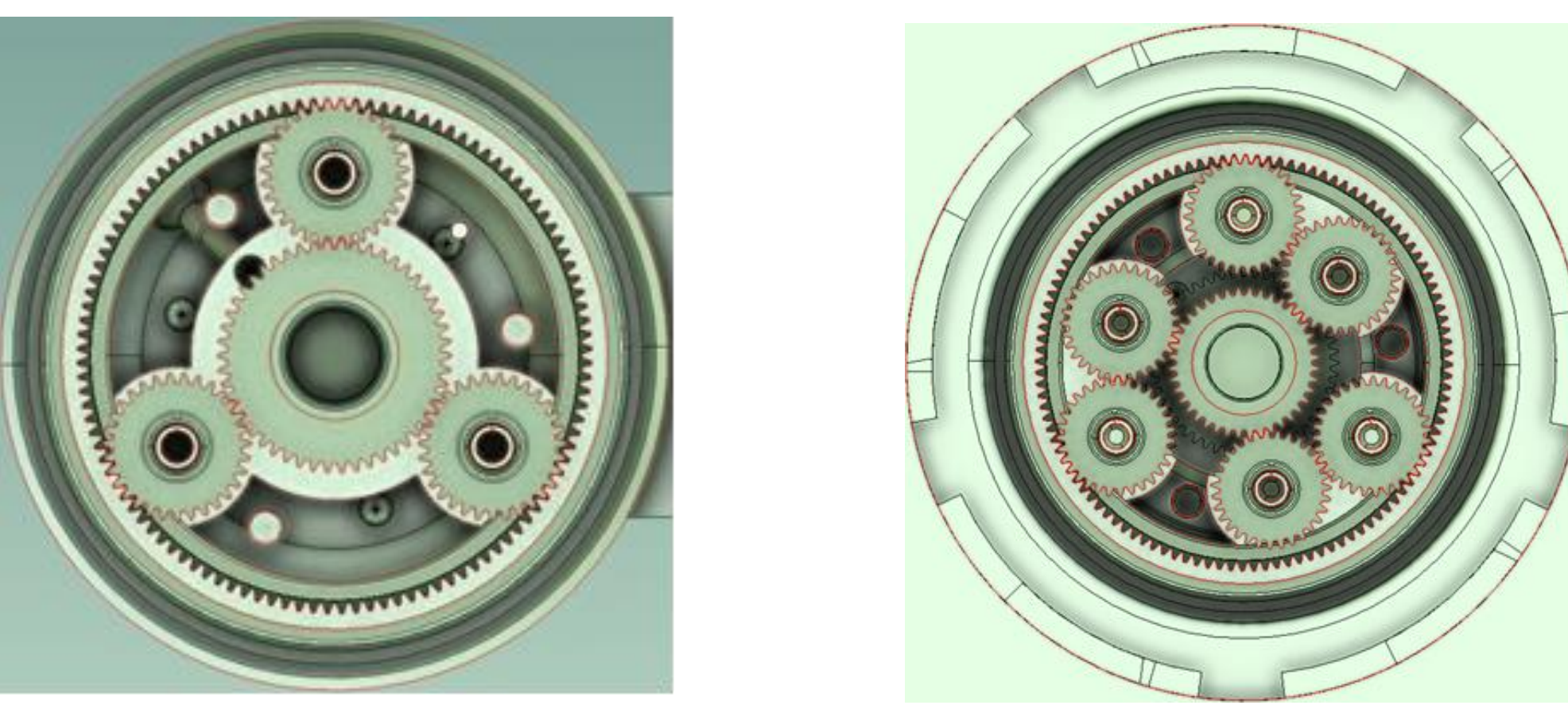

\section{Project Partner}

Hochschule Konstanz Technik, Wirtschaft und Gestaltung CONTEC GmbH

SAT Kerntechnik GmbH

\section{Test bench}

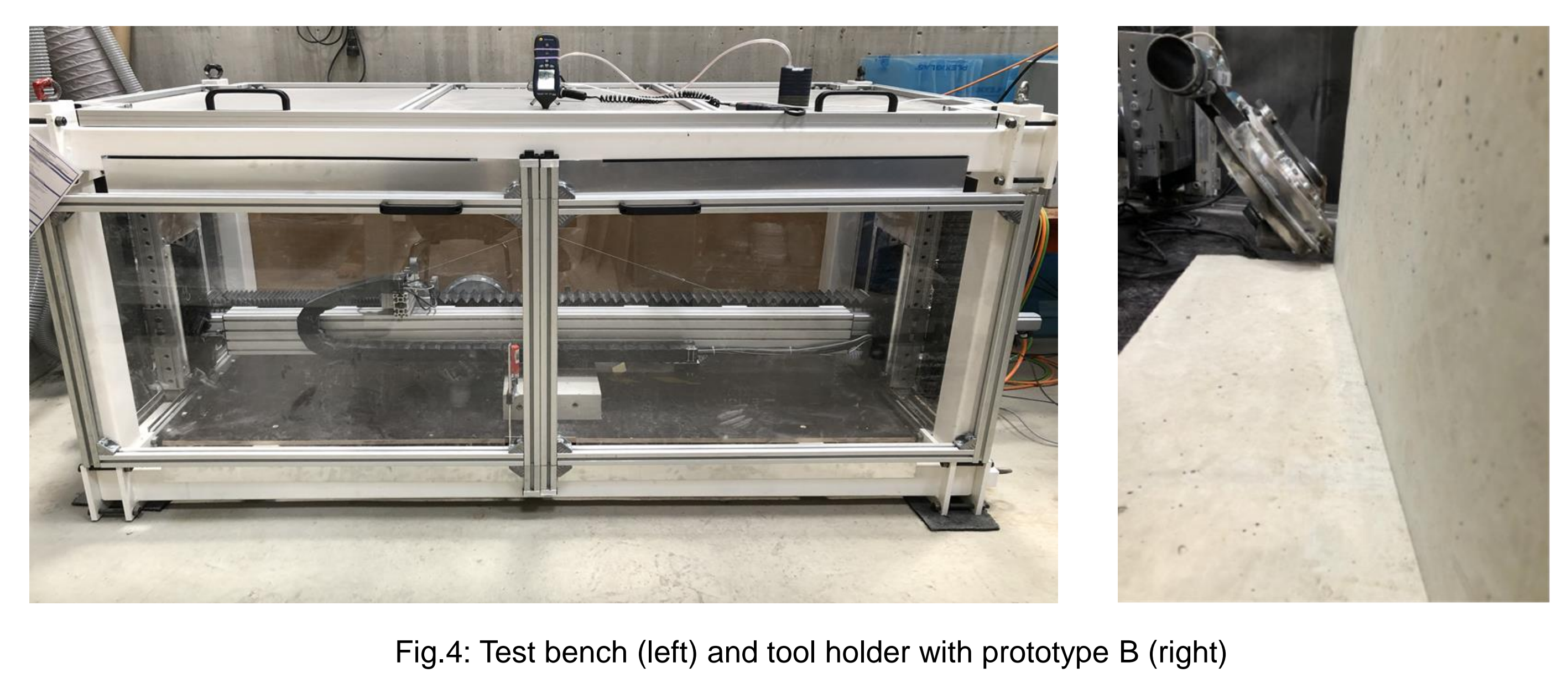

\section{Test results}
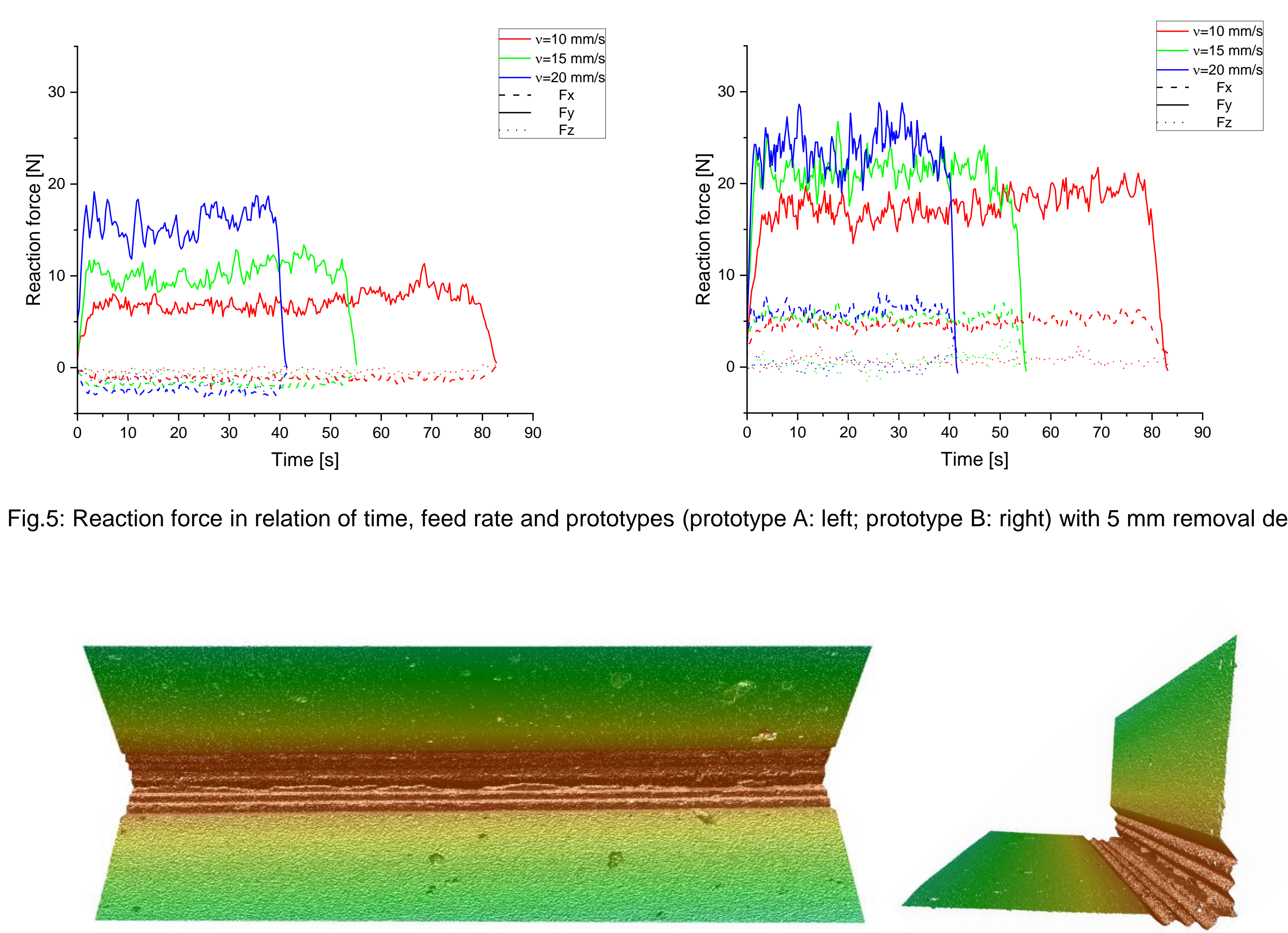

Fig.6: 3D displays for the inner edge after the test with the prototype B

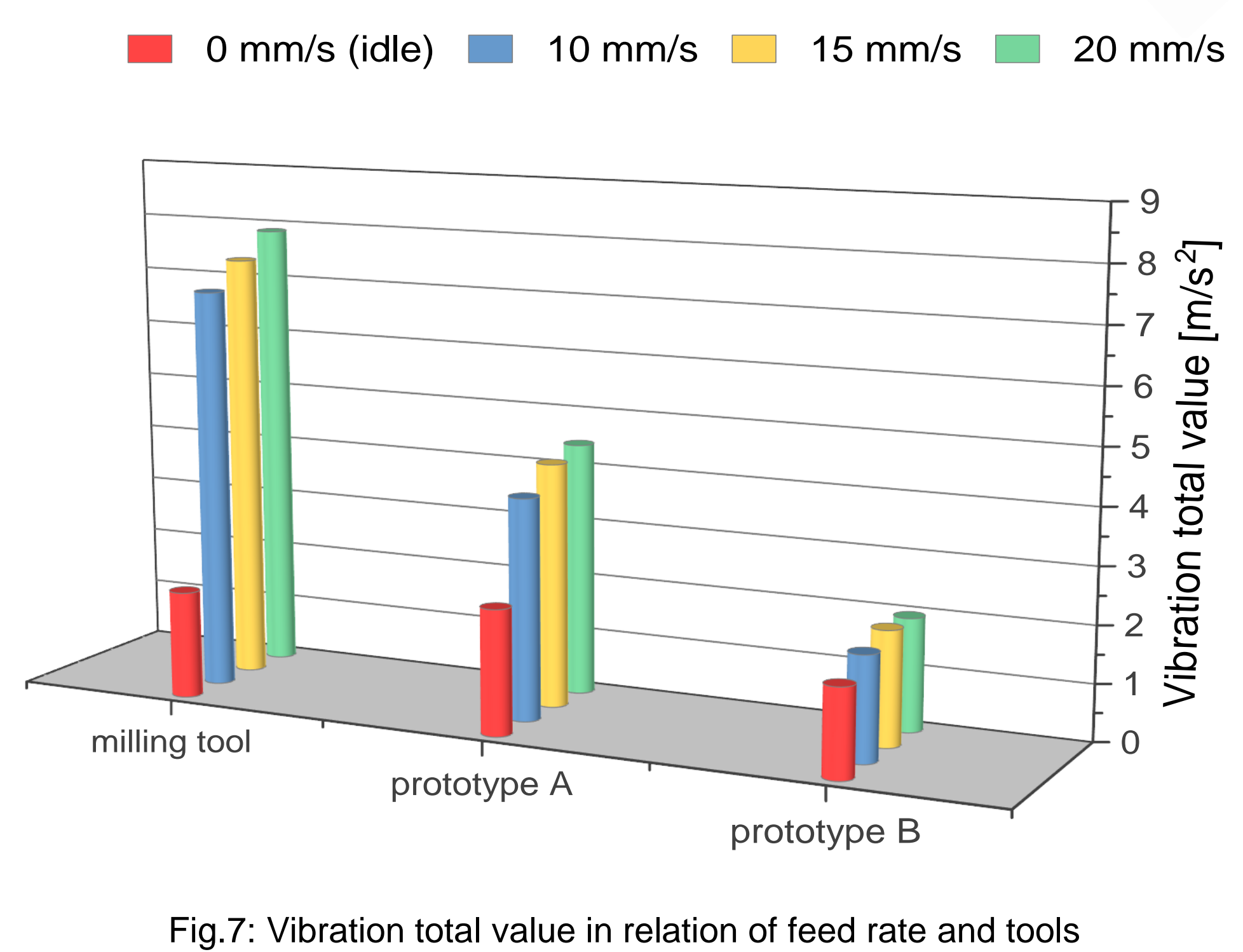

\section{CNNEC Made in Germany}

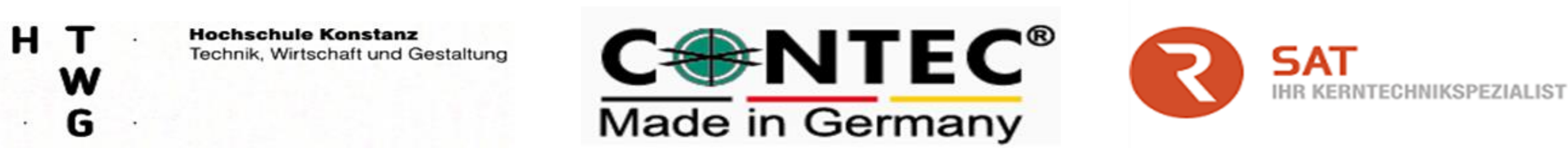

\section{Karlsruhe Institute of Technology (KIT)}

\section{Institute of Technology and Management in Construction (TMB)}

Prof. Dr.-Ing. Sascha Gentes, Tel.: +49 721 608-46546, E-Mail: sascha.gentes@kit.edu

M.Sc. Shanyao Zhang, Tel.: +49 721 608-48228, E-Mail: shanyao.zhang@kit.edu 